\title{
Role of brain-derived neurotrophic factor in shaping the behavioural response to environmental stressors
}

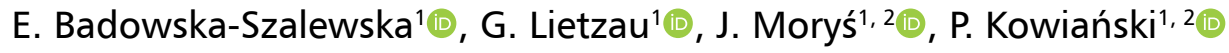 \\ ${ }^{1}$ Department of Anatomy and Neurobiology, Faculty of Medicine, Medical University of Gdansk, Poland \\ 2Institute of Health Sciences, Pomeranian University of Slupsk, Poland
}

[Received: 28 July 2021; Accepted: 5 August 2021; Early publication date: 7 August 2021]

Brain-derived neurotrophic factor (BDNF) is an important neurotrophin involved in an integration of the brain activity in physiological and pathological conditions, with formation of a short- and long-term functional and structural neuroplasticity. This process proceeds, with a changeable dynamics, in the subsequent stages of ontogenesis. In addition to many other functions in the central nervous system, $B D N F$ is also involved in shaping a response to stress stimuli in the form of precisely adjusted behavioural reactions involving the limbic system, and the endocrine system with stimulation of the hypothalamic-pituitary-adrenal axis (HPA). Although almost every stressor increases the activity of the HPA, the neuronal response to it can vary substantially. This may be due to involvement of different neurotransmitter pathways, neuromodulators and neurohormones, as well as changes in gene expression. It is widely accepted that BDNF synthesis and secretion are modulated by stress. Furthermore, age is an important factor influencing the BDNF expression in response to different stressors. In this work, we focused on the analysis of the role of mild stressful stimuli, which commonly occur in the natural environment, on changes in BDNF expression at various stages of ontogenetic development. Although, the presented data comes from animal studies, probably similar mechanisms of stress regulation are also present in humans.

This comprehensive review shows that the influence of stressors on the BDNF expression depends on many factors, including a type and duration of a stressor, time of neurotrophin detection, animal's resistance to stress, brain area, and genotypic characteristics of an individual. A more detailed understanding of the mechanisms shaping stress reactions, including the role of BDNF, may be of both theoretical and practical importance, allowing designing more effective strategies for preventing and treating stress itself and the stress-related disorders. (Folia Morphol 2021; 80, 3: 487-504)

Key words: aging, brain-derived neurotrophic factor (BDNF), glucocorticoids, ontogenesis, stress

Address for correspondence: G. Lietzau, PhD, Department of Anatomy and Neurobiology, Faculty of Medicine, Medical University of Gdansk, ul. Dębinki 1, 80-211 Gdańsk, Poland, tel: +48 58349 1819, e-mail: grazyna.lietzau@gumed.edu.pl 


\section{INTRODUCTION}

Animal behaviour is a result of a coordinated action of functional systems within the central nervous system (CNS). The behaviour is a consequence of a reaction to external stimuli of different modalities, as well as the effect of a response to constantly changing parameters of internal environment in the organism. Finally, it is a consequence of elaborated reactions resulting from the conscious integration of stimuli in the brain cortical areas, reflexes, and instinctive or emotional reactions arising in subcortical structures of the brain. Stress stimuli of various natures, constantly affecting the body, play an important role in shaping the behaviour. Therefore, answering to these stimuli is an integral part of functioning in the natural environment. The reaction to stressful stimuli requires involvement and activation of many systems. In addition to the sensory and motor systems, they include the vegetative, endocrine and limbic systems, as well as various neurotransmitters, neuromodulators and signalling pathways, leading to changes in expression of transcription factors and gene activation. It is worth noting that the reaction to stressful stimuli is plastic and depends on interaction of numerous external and internal factors. It also changes its characteristics along ontogenetic development. One of the important factors shaping the response to stressful stimuli is brain-derived neurotrophic factor (BDNF). Despite systematic research, the role of this factor in shaping responses to different types of stressors at various stages of ontogenetic development is not fully elucidated. In research on the role of this factor many experimental models have been introduced to approximate the conditions of the stressors' action in the natural environment. This review summarises the current knowledge on the role of BDNF in stress at various stages of ontogenesis. A brief overview of the most commonly used tests to assess the expression of BDNF in response to stress stimuli is also presented.

\section{STRESS REACTION MECHANISIMS INTEGRATE FUNCTIONS OF THE ENDOCRINE, LIMBIC AND AUTONOMIC SYSTEMS}

One of the most important functions of the nervous system is perception and transfer of information from both external and internal environment to the complex functional systems of the brain. This enables integration of stimuli and maintenance of physiological homeostasis, as well as elaboration of an adequate behavioural response. One of the most important systems involved in these processes is the hypothalamic-pituitary-adrenal axis (HPA) [67, 112, 157, 162]. Hypothalamus enables transfer and integration of neurogenic signals to the endocrine, limbic and autonomic systems. Within hypothalamus, the paraventricular nucleus (PVN) and, to a lesser extent, the supraoptic nucleus (SON) are the two areas involved in the stress response initiation $[26,169]$ and shaping this reaction, depending on the stressors' specificity $[52,105]$.

Taking into account the anatomical aspects related to the stimuli transfer between different functional systems in the brain, it can be suggested that influence of stressors on the HPA occurs in two ways: direct and indirect. The first one is used by physical stressors activating HPA directly $[42,67]$. The second one is used by emotional stressors, influencing the HPA through activation of important structures of the limbic system, such as amygdala and hippocampus $[23,55,130]$. Activation of hypothalamus results in a rapid secretion of corticotrophin releasing hormone $(\mathrm{CRH})$ - from the small cellular part of the PVN, and arginine-vasopressin (AVP) — from the large cellular part of this nucleus and from the supraoptic nucleus (SON). It is followed by a release of the adrenocorticotropic hormone $(\mathrm{ACTH})$ from the pituitary gland [15, 108] and, ultimately, glucocorticoids or corticosterone from the adrenal cortex [69, 112]. Glucocorticoids, due to the negative feedback, influence hypothalamus and pituitary gland and inhibit the production of $\mathrm{CRH}$ and $A C T H$, respectively. This, in turn, results in reduction the HPA activity [68]. Despite the adaptive action of glucocorticoids in the short term, their long-term action lowers the body's ability to cope with stress and may affect the synaptic plasticity [100, 102].

\section{INTERACTION OF GLUCOCORTICOIDS, NEUROTRANSMITTERS, AND BDNF IS NECESSARY TO ELABORATE THE STRESS REACTION}

Stress may evoke changes in BDNF expression through signalling pathways triggered by glucocorticosteroids (glucocorticoids) $[48,86]$. Barbany and Persson [16] reported that excessively high or low levels of glucocorticoids may alter the BDNF expression. It has been suggested that BDNF may reduce some of the negative effects of glucocorticoids [90] and its direct administration is able to restore the stress-reduced content of this neurotrophin, e.g. in the hippocampus [27, 82]. However, the results of these studies are inconclusive and not commonly ac- 
cepted [63]. The interaction between glucocorticoids and BDNF can occur, among others, through their influence on expression of the TrkB receptor [72]. The studies conducted in animals with adrenalectomy (removal of adrenal glands) indicated that glucocorticoids negatively affected the BDNF expression in hippocampus and other cortical areas [71, 119, 150, 151]. However, adrenalectomy does not completely block the effects of stress on the BDNF concentration [151]. There is evidence that other factors, such as interleukin-1 $\beta$, also contribute to the changes in the BDNF expression in hippocampus [17]. Also the animal activity is an important factor regulating the BDNF production in the rat hypothalamus [97]. The regulation involves classical neurotransmitters, such as glutamate, acetylcholine, serotonin and GABA [65, $76,96]$. It has been suggested that whereas glutamate, acetylcholine and serotonin increase the BDNF expression, GABA reduces its content in the CNS.

\section{BDNF CONTRIBUTES TO MODIFICATION OF THE HPA ACTIVITY IN STRESS CONDITIONS}

The role of stress as modulator of BDNF synthesis and release is well documented $[108,109]$. The longterm stress affects the expression of genes responsible for signalling pathways related to glucocorticoids and neurotrophins, among them also BDNF [51, 54, $114,159,178]$. Transcription of BDNF is under control of promoters which react differently to endogenous and exogenous stimuli (e.g. glucocorticoids and environmental factors, respectively) [80]. These stimuli are also responsible for triggering epigenetic modifications [155]. It is believed that epigenetic processes cause long-lasting or permanent changes in BDNF gene expression, which is reflected in the behavioural responses occurring during early development $[130,168]$. Methylation of the BDNF gene is an important epigenetic process affecting its expression, thus inducing changes in the protein content initiated by stress. However, the consequences of this modification are differently interpreted by some authors [114]. The reason for this could be epigenetic changes at different loci within the same gene [91]. Additionally, there is evidence showing that changes in BDNF expression were also related with age [91]. It has been suggested that epigenetic modification of BDNF gene may be responsible for an occurrence of some pathologies induced by chronic stress, such as mental disorders or cognitive decline $[167,177]$.
Animal studies showed that chronic social stress in mice reduced BDNF expression in the hippocampus as a result of methylation within its gene [156].

Brain-derived neurotrophic factor plays an important role in integrating neuronal and endocrine responses to different stressors [140]. This is due to the direct influence of this neurotrophin on the HPA $[73,154]$. Studies showed that both endogenous (already existing pool) and de novo synthesised BDNF regulated the HPA functioning and elaboration of an adaptive stress response [108]. It has been shown that a single injection of BDNF causes activation of the HPA [58]. Importantly, by modifying the HPA activity, BDNF facilitates adaptation to environmental conditions [140] and contributes to the maintenance of the physiological homeostasis [154]. By counteracting the adverse effects of glucocorticoids, BDNF is an important factor reducing the stress-induced psychosocial and psychological symptoms [90]. As mentioned before, the BDNF function in response to stressors relays on regulation of synthesis and release of hormones and neuropeptides, such as CRH and AVP in PVN and SON $[4,58,97,119]$. The stress-induced increase in the BDNF concentration stimulates AVP and $\mathrm{CRH}$ synthesis $[58,97,119]$. It may also affect the intracellular content of neuropeptides [58].

\section{REGULATORY ROLE OF BDNF IN SHAPING THE BEHAVIOURAL RESPONSE IS DETERMINED BY NEURONAL ACTIVITY AND FUNCTION, AS WELL AS STAGE OF ONTOGENETIC DEVELOPMENT}

Brain-derived neurotrophic factor has important regulatory functions in neurons within the CNS, regardless of the stage of ontogenetic development [154]. The role of this neurotrophin is related to the activity of neural networks and synaptic plasticity, and it can differ depending on the stage of ontogenesis $[58,60,90,93,146]$. Neural activity affects the BDNF gene transcription, as well as synthesis of the BDNF protein. It also determines an expression of TrkB receptor, which is one of the most important signal transducers of this neurotrophin [61].

In the earliest stage of ontogenetic development, BDNF is involved in differentiation of neural stem cells into neurons, their growth and maturation $[31,175]$. This is a consequence of BDNF regulatory function upon cell proliferation and migration, neuronal survival, as well as maturation of the axodendritic system and synaptogenesis $[123,175]$. 
In the mature brain, BDNF regulates synaptic transmission [160] and has a protective function upon neurons [7, 89]. Consequently, BDNF has a role in promoting learning, cognitive and memory skills, as well as reduction of anxiety [37, 38]. During aging, BDNF is responsible for preventing neuronal degeneration, as well as for an enhancement of the regenerative and repair processes [98, 145, 154]. In many brain areas, including limbic structures such as hippocampus, amygdala and the hypothalamic nuclei, BDNF has been suggested to modulate the behavioural responses to stress [109, 116, 119]. However, its role in this process differs depending on the stage of development and brain area [93].

The variety of BDNF functions in the CNS suggests that alterations in the expression of this neurotrophic factor could be involved in the pathophysiology of the stress-related behaviours caused by long-term effects of stressful stimuli, such as orientation, memory and cognition disturbances and mental illnesses, such as depression, Parkinson's, Alzheimer's and Huntington's diseases [5, 104, 114]. Therefore, BDNF could be considered in future research on therapeutic agents aimed at treatment of several stress-related disorders.

\section{CHANGES IN BDNF EXPRESSION DURING ONTOGENESIS AFFECT STRESS REACTIONS}

Stimulation of the CNS with a mild stress evokes multidirectional effects. One of the ways in which this modification occurs is through activation of the HPA and its relationship with BDNF. This is indirectly related to involvement of BDNF in development of synaptic plasticity $[58,60,79]$. The intensity of this process varies during different stages of ontogenesis, which can be a consequence of changes in BDNF concentration $[58,108]$. Following, we briefly discuss the CNS effects induced by the selected mild stressors (i.e. causing neither structural damage nor pain) often present in the animal's natural environment.

\section{Early development}

An early developmental stage, in rodents lasting approximately 2 weeks after birth, is called a stress hypo-responsive period (SHRP) [87, 132, 137]. During this time, activation of the HPA and a complete development of the stress response occur only after action of very strong psychological or physical stimuli [43, 139]. One can suspect that attenuation of the stress response during that time may protect the developing brain from negative effects of stress hormones (e.g. glucocorticoids) [132]. The high threshold of the HPA activation could be a consequence of the incomplete development of structures which control the stress response, one of which is PVN $[125,128]$. It is also associated with a less efficient cooperation of the structures controlling the HPA [44].

Stress in the early period of life negatively affects development and functioning of the brain. It may be responsible for inducing anxiety, depression, and aggression also persisting later in life $[2,29,70,166]$. However, in general, connection of stress occurring in the early life with psychopathological symptoms observed in adulthood is poorly understood and requires further research [167].

Maternal separation and social isolation. Maternal separation (MS) and social isolation (SI) are regarded as the most common causes of stress in the early life. Early periodic postpartum MS, as well as siblings SI are examples of stress that can cause disturbances in the HPA activity resulting in structural and functional impairments in later life [122, 126, 174, 177]. These two forms of stress in the early life also affect the BDNF mRNA and protein levels. The long-term MS-induced changes in the BDNF expression level in the hippocampus [21, 41] have been linked to learning and memory disorders [2, 30, 70, 174]. Ohta Ken-ichi et al. [111] showed that a long-term separation (6-h) from a mother, between postnatal day P2 and P20, reduced the expression of the BDNF genes in hippocampus of the Sprague-Dawley rats at P7. However, it had no effect on BDNF-ERK signalling after P14. MS between P2 and P14 induced a transient increase in the BDNF levels in hippocampus, prefrontal cortex [126], and amygdala of the Wistar rats [34]. Other studies showed that an early weaning (during the first week of life) had no effect on the BDNF levels in hippocampus [179]. BDNF increase was observed in the olfactory bulb, where this neurotrophic factor may play an important role in learning of the olfactory association [179]. The results confirm that stress sensitivity is lower and the HPA axis response is decreased in the early postnatal period [87, 132]. They also suggest that period of hyporesponsiveness to stress and duration of the postpartum MS may be important factors inducing changes in the BDNF expression in the various brain regions. It has been assumed that BDNF plays an important role in neuroprotection [92]. Hence, an increase of its expression could counteract the effects 
of MS. However, there are data indicating that MS induced a decrease in the BDNF expression within 3 weeks after birth [33]. This stressor also induced a reduction in the BDNF mRNA in P16, followed by an increase in P30 and P60 in hippocampus [83] and in the medial prefrontal cortex (MPFC) of Wistar rats [174]. A long-term MS induces reduction in the number of dendritic spines and delay in maturation of the pyramidal neurons in hippocampus [111]. Thus, the MS may influence the BDNF-associated signalling during synaptogenesis [111]. These processes and an increased apoptosis coexist in the early postnatal period [29]. These observations indicate that the MS-induced abnormalities in hippocampus are associated with disturbances in the BDNF signalling pathway during the early brain development [111]. Studies showed that the burden of MS in rodents was responsible for changes in BDNF expression in adulthood and aging, often leading to emotional and cognitive disturbances [122]. Hence, MS causes a decrease in the BDNF concentration, which may lay at the basis of some characteristic functional disorders. A potential factor contributing to these processes are epigenetic changes in the BDNF gene, which may increase susceptibility to stress later in life [141].

In adult and older rodents, the long-term MS also resulted in reduction of BDNF expression in hippocampus $[2,45,94,152]$. Furthermore, in adult rats, a decrease in BDNF was observed in amygdala [124] and prefrontal cortex [126]. However, in adult rats additionally subjected to prolonged swimming stress, no further reduction in BDNF expression in the prefrontal cortex was reported [126]. It is possible that a decrease in BDNF expression in the CNS early in life can result in an impairment of the plasticity mechanisms later on.

The results of studies investigating changes in BDNF expression after MS are not equivocal. Récamier-Carballo et al. [122] observed an increase in BDNF concentration in hippocampus and amygdala and a decrease in the frontal cortex in adult mice after the long-term MS. Study by Greisen et al. [62] showed an increase in BDNF concentration in hippocampus in adult rats subjected previously to MS in their early life, although they found no changes in the frontal cortex and PVN. On the contrary, van Zyl et al. [164] showed no effect of MS and a restraint stress on BDNF content in hippocampus of adult rats. These differences could be explained by the selection of various species and strains of experimental animals, differences in the experimental conditions and protocols concerning for example the time-point of the expression measurement of the neurotrophic factor.

Thus, various changes in BDNF expression were demonstrated in different brain areas, both in animals after MS and those subjected to additional stress in adulthood. This suggests the complexity of the regulatory mechanisms. The increase in BDNF expression in hippocampus of rats after MS could be a compensatory response to neonatal separation, keeping neurogenesis unchanged in adult animals. Reports on the SI effects on the CNS and especially their pathophysiological consequences are not equivocal. Biggio et al. [21] have shown that both $3 \mathrm{~h}$ MS between $\mathrm{P} 3$ and $\mathrm{P} 14$ and $\mathrm{Sl}$ after weaning induce a significant reduction in BDNF expression in hippocampus of Sprague-Dawley rats. Despite the opinion that early SI exacerbates responses to stressors [167], its effects in adulthood are poorly understood.

\section{Maturation}

The maturation (from P14 to P90) is a phase of a rapid structural and functional changes relaying on an intense development and reorganization of brain structures, including final shaping of their connections. In this phase, the structures involved in the stress response undergo further development. During this period, they are more sensitive to aversive stimuli then in the adulthood $[99,106]$. In adolescence, a response of the HPA to stressors is increased and prolonged $[9,93,107]$. This results in an increased concentration of glucocorticoids and a prolonged time of their secretion after a repeated exposure to a stressor $[99,165]$. It may be a consequence of the incomplete development of the HPA feedback inhibition [59, 93]. According to some authors, this can explain the insufficient control of its activity $[9,93,99]$. Numerous studies have shown that exposure to potentially traumatic stressors in adolescence has a significant impact on the further development of brain structures and formation of their connections [9, 36, 158]. In development, stress triggers processes resulting in permanent changes in the neuronal plasticity and efficiency of the synaptic connections, which require the BDNF activity $[18,63]$. Many authors emphasize that changes of environmental conditions influencing sexually immature animals, with not completely formed neuroendocrine regulatory mechanisms and neuronal connections, may lead to the long-term physiological and behavioural dysfunctions $[24,66]$. 
Predator odour and social isolation. The predator smell is a strong, unconditional and psychogenic stressor for the rodents $[18,153,180]$. Animals exposed to this stressor demonstrate changes in activity, long-lasting and augmented anxiety behaviour $[153,180]$. They are accompanied by an increased level of glucocorticoid release and an altered BDNF concentration [18]. The nature of the response to a predator's threat early in life is a species-specific feature. It is often associated with development of defensive behaviour and sensitivity to stress during later development $[18,153,180]$.

Bazak et al. [18] assessed BDNF expression in the frontal associative cortex, CA1, CA3 sectors of hippocampus and the dentate gyrus (DG), after a single (10 $\mathrm{min}$ ) and multiple exposures to a predator urine scent in the Sprague-Dawley rats at P24. The experiment was repeated at P60. It was found that both the early and late effects of the stressor induced a significant reduction in the BDNF MRNA and BDNF protein levels in the hippocampal CA1. The effect of re-exposure to stress was greater in rats exposed to the same stressor again, indicating a cumulative effect of this kind of stimulus.

Exposure to a chronic psychosocial stress may also alter the BDNF expression. A long-term SI caused changes in functioning of the HPA and an increase of anxiety and depressive behaviours [177]. They were accompanied by a reduction of the BDNF mRNA and BDNF protein concentration in hippocampus of the adolescent rodents. This suggests an important role of this type of stressor in the regulation of the BDNF content in the limbic system and, thus, in shaping the adequate behavioural responses during further stages of ontogenesis. However, consequences of these processes for the synaptic plasticity and the brain structure in the adulthood remain unknown.

Chronic mild stress. Several procedures can induce mild forms of stress. Among the most frequently used are: temporary deprivation of food or water, overcrowding in a cage, social isolation, using a soaked sawdust in a cage or tilting frames $\left(45^{\circ}\right)$, inversion of the light/dark cycle, and a short-term (5 $\mathrm{min}$ ) forced swimming test [155]. These stressors applied in the Spraque-Dawley rats resulted in a reduction of BDNF mRNA in hippocampus and an induction of morphological and functional changes in the spino-dendritic system [155]. A decrease in the BDNF mRNA expression in hippocampus was also reported after application of a chronic, unpredictable, mild stress, in form of the open field test, for 8 to 28 days, in 2-month-old Spraque-Dawley rats [142]. These results confirm the possibility of using many types of mild stressors in modelling responses to harmless stimuli present in the natural environment of rodents. This gives the possibility of their use in studies on behavioural responses in animals at different ages and under influence of stimuli of various nature and duration.

Immobilisation. An immobilisation stress (IM) induces the BDNF expression [95]. It is responsible for the structural plasticity changes in hippocampus and amygdala, i.e. areas involved in development of cognitive and affective symptoms of stress [136]. The effects of an acute and chronic immobilisation stress on the level of BDNF expression were observed in the 8-week-old Wistar rats [84]. A day following $2 \mathrm{~h}$ immobilisation, the BDNF level increased in neurons of the basolateral amygdala (BLA), although it did not change in the CA3 sector of hippocampus. However, after a long-term $(8 \mathrm{~h})$ immobilisation, the BDNF level increased in the BLA and decreased in CA3. Additionally, the BLA neurons hypertrophy and the hippocampal CA3 neuronal atrophy were observed. In line with these results, Ueyama et al. [161] reported a reduction of the BDNF mRNA level after $8 \mathrm{~h}$ immobilisation stress in hippocampus of the 6-week-old male Wistar rats.

Forced swimming. A forced swimming (FS) stress is a type of stimulus experienced by rats in their natural environment [40]. Chronic FS combines psychological stimuli of novelty and an aquatic environment with a physical stimulus in the form of the forced motor activity [42]. In the 2-month-old juvenile Sprague-Dawley rats, a short-term (10 $\mathrm{min}$ ) FS test in cold water caused a rapid increase in the BDNF mRNA and BDNF protein concentration in hippocampus, already $15 \mathrm{~min}$ after the end of stimulation. However, after chronic FS (10 min/21 days in $25^{\circ} \mathrm{C}$ water), the BDNF $m R N A$ and protein expression in hippocampus decreased after $60 \mathrm{~min}$ from its termination [143]. Badowska-Szalewska et al. [13] assessed the effects of the long-term $\mathrm{FS}\left(15 \mathrm{~min} / 21\right.$ days in $22^{\circ} \mathrm{C}$ water) on the density of BDNF-containing neurons in the pyramidal layer of the hippocampal CA1, CA3 sectors and the granular neurons of DG, as well as in SON and PVN nuclei of the hypothalamus, in juvenile (P28) and middle-aged (P360) Wistar rats [13, 53]. They reported a decrease in the density of the BDNF-ir neurons in CA1 and DG and in the nuclei of the hypothalamus. 
It was concluded that the type of the stressor determined the changes in number of the BDNF-ir cells in juvenile rats. The different density of BDNF-ir in juvenile versus middle-aged rats can be explained by age-related changes in the demand for BDNF [13, 53]. Exposure to a mild long-term stress early in life is believed to attenuate the HPA inhibition, which may lead to an increase in the glucocorticoid levels $[74,99]$, as well as to a decrease in BDNF expression. Importantly, this may result in an impairment of the neuroplasticity and of the normal brain development at subsequent stages of ontogenesis. Consequently, this may also initiate formation of improper behavioural reactions during subsequent life periods.

High light-open field stress. The high light-open field (HL-OF) test reflects conditions in which the rats actively explore a new environment $[46,53]$. The aversive stimulus in the form of a bright light can trigger emotional reactions and anxiety behaviours $[64,118]$. However, a chronic exposure to HL-OF (15 min/21 day cycle), changed the density of the BDNF-ir neurons neither in the large-cell (PVm) and small-cell (PVp) part of the PVN, nor in the SON of the hypothalamus, in the Wistar rats in P28 [53]. This can be explained by an adaptation to the particular types of stressors [46]. According to some authors, it may be the result of the BDNF-dependent plasticity within particular brain structures, and it suggests a protective role of BDNF in the neurons of these areas [146].

\section{Adulthood}

Reaching a complete morphological and functional maturity the animal's activity and behaviour becomes characteristic for the adult representatives of particular species. This is related to the intensification of its interaction with the surrounding environment and, thus, an increased susceptibility to the stressful stimuli. As a result, in stress studies on adult animals a wide range of tests approximating the impact of stressors occurring in the natural environment is used $[4,6,58,108,119]$. Adulthood is characterised by the HPA functional efficiency $[6,58]$. Most of studies investigating the role of BDNF in hypothalamus and/ /or other structures involved in the HPA regulation in response to stress are performed in the adult rats.

It is worth mentioning that neurogenesis in the adult brain occurs in two main areas, the subventricular zone of the lateral ventricles and the subgranular zone of the dentate gyrus of the hippocampus [39]. Especially the latter area of proliferation is important for the proper shaping of processes related to spatial and contextual memory of stress-related events and reactions $[49,50,101]$. The effect of stressful stimuli is related to the reduction of neurogenesis and, consequently, it is also associated with a decrease in BDNF expression [47]. A further consequence of these processes is the disturbance of structural and functional plasticity in the hippocampus.

Restraint and immobilisation. Restraint and immobilisation stresses (RS and IM, respectively) combine the effects of psychological and physical stimuli $[32,147]$. This combination of stressors occurs sporadically in the natural environment of rats. As expected, a complete immobilisation of an animal is more aversive than restricting its movements. Most studies on the effect of such stimulation on BDNF expression were focused on hippocampus. However, the results of studies investigating the BDNF mRNA and its protein level after stimulation by the acute or chronic RS or IM are unequivocal and inconclusive. Both acute ( $6 \mathrm{~h}$ ) RS and chronic RS (lasting from 1 to 3 weeks) induced a marked reduction in the BDNF mRNA levels in hippocampus of the Sprague-Dawley rats [107] and C57BL/6J mice, and BALB/CJ mice [3]. Similarly, a decrease in BDNF level in the hippocampal pyramidal cell layer and in the granular layer of the DG was reported after 1 day in the $4 \mathrm{~h} / 3$ days RS rat model [172]. In line with the previous results, $\mathrm{Xu}$ et al. [171] observed a decrease in BDNF expression and the neuronal proliferation in hippocampus after longterm ( $6 \mathrm{~h} / 14$ days) RS. Other authors showed that although the chronic RS leads to decrease in BDNF and the BDNF mRNA expression in the hippocampal CA3, it could initiate its increase in the BLA [19]. A significant decrease in the BDNF level after a single $3 \mathrm{~h}$ RS was also observed in the prefrontal cortex (PFC) of the Wistar rats [120]. However, Naert et al. [108] showed an increase in BDNF levels after chronic RS ( $3 \mathrm{~h} / 21$ days), not only in the hippocampus but also in the hypothalamus and pituitary gland in the Sprague-Dawley rats. Interestingly, there are also reports stating that an acute $(3 \mathrm{~h})$ and chronic ( $6 \mathrm{~h} / 14$ days) RS did not induce any changes in the BDNF mRNA levels or BDNF protein concentration in hippocampus and amygdala [121, 127].

Immobilisation for $2 \mathrm{~h}$ caused a decrease in the level of BDNF mRNA in hippocampus in the Sprague-Dawley rats, immediately after the end of the experiment [176]. Chronic IM reduced the BDNF levels and BDNF immunoreactivity in the hippocampal 
pyramidal neurons, as well as in the DG granular neurons, in the Sprague-Dawley rats [173]. A comparison of the effect of 7-day vs. 21-day IM on the BDNF level in the C57BL/6J mice showed that after 21 days of this type of stress the BDNF level in hippocampus was lower than in the 7-day group [25].

The available data suggest an importance of the time of BDNF concentration measurement after performing the experiment, stressing the possibility of its fluctuations. Marmigère et al. [95] have shown that after a short-term (15 or $60 \mathrm{~min}$ ) IM the BDNF mRNA level increased rapidly and then decreased approximately $2-3 \mathrm{~h}$ after the stressor termination. Similarly, after 180 min exposure to IM, BDNF expression initially increased, then decreased to the level observed in the control group [95]. Moreover, it was also revealed that IM as a stressor can transiently increase BDNF expression, despite high levels of stress hormones [95]. These observations suggest that the rapid changes in BDNF concentration in hippocampus may be a part of the strong compensatory response triggered to maintain homeostasis, or suggest induction of the neuronal plasticity mechanisms triggered in animals when confronted with new stimuli.

Interesting effects on BDNF expression were observed in experiments with combination of stress and learning stimuli. In response to both acute and repeated IM stress, BDNF expression decreased in hippocampus [133]. However, animals additionally subjected to learning showed an increased expression of BDNF in comparison to those which were only stressed. Thus, learning and stress have the opposite effect on BDNF level and the effect of learning, leading to an increase in BDNF, is outweighing the stress effect. This observation may be of important practical significance for modifying animals' behaviour.

An analysis of impact of the IM on the level of the BDNF mRNA in various brain areas showed significant differences between them. One-time $2 \mathrm{~h}$ or $8 \mathrm{~h} \mathrm{im-}$ mobilisation, as well as chronic ( $2 \mathrm{~h} /$ day, for 7 days) immobilisation caused a decrease in the BDNF mRNA level not only in the hippocampal sectors, DG but also in hypothalamus and several cortical areas of the Sprague-Dawley and Fischer 344/N rats [149-151]. On the other hand, a short-term (15 min) IM caused a significant increase in the BDNF mRNA and protein expression in PVN and SON in hypothalamus [119]. Numerous studies showed that both short-term $(2 \mathrm{~h})$ and longer, repeated ( 7 days $/ 2 \times$ daily) immobilisation increased the level of BDNF mRNA in the PVN, lateral part of the hypothalamus and pituitary in the Sprague-Dawley and Fischer 344/N rats [149-151]. Fluctuations in the BDNF content, resulting from changes in the expression of genes regulated by the concentration of stress hormones, may contribute to alterations in a density of dendritic spines in structures of the limbic system [19]. A consequence of decreased BDNF expression may be structural changes and neuronal loss [148].

The diversity of the presented results, and a high dependence of BDNF level on duration of exposure to the stressor and its type, suggests the existence of complex regulatory mechanisms responsible for expression of BDNF mRNA and its protein in the CNS. One can expect significant differences in these mechanisms among various brain areas.

Social stress, social defeat stress. Pattern of BDNF expression in rodents, resulting from changing social hierarchy and living conditions modified in experiments, were the subject of previous studies [10, $134,138]$. Modified housing conditions and social hierarchy in the experimental animals (social stress) are natural stressors that can influence physiological parameters and behaviour [134]. A short-term (10 min) social stress in mice led to a decrease in BDNF mRNA content, $24 \mathrm{~h}$ after stimulation, in the CA1, CA3 sectors of hippocampus, DG, BLA, piriform cortex, thalamus and hypothalamus [116]. The BDNF mRNA levels normalised after approximately 5 days. According to the authors, the BDNF changes may be responsible for reactions relaying on inhibition of the territory defence behaviours and anxiety.

Changes in housing conditions and social stress are long-term acting stressful factors $[10,138]$. Neither 7 nor 21 days of the social stress, based on exchanging animals in cages, influenced the BDNF level in hippocampus in C57BL/6J mice [25]. An exposure of the NMRI mice to 4 weeks of an intermittent stressor (by placing animals in a new cage or social hazard conditions) increased the BDNF expression in hippocampus among the socially endangered animals, but not in the mice placed in a new cage [113]. This can be explained by the role of BDNF in supporting mechanisms promoting behaviour related to defence of territory and offspring.

Other interesting observations come from studies conducted in a model which mimics conditions of the "isolation syndrome" and is based on depriving animals of social stimuli by placing them individually in cages [163]. The assessment of BDNF levels in 
hippocampus, frontal cortex, hypothalamus, striatum and midbrain in C57BL/6J mice subjected to long-term social stress or social deprivation showed significant differences compared to the group with a stable social structure [20]. In the group of animals subjected to the social deprivation, an increased activity of the HPA and a lower level of BDNF were demonstrated in the examined brain areas, in comparison to animals from the group with the stable social structure. Thus, the chronic social deprivation, as opposed to the social instability, has been found to lead to emotional disturbance and neuroendocrine activation, combined with decreased BDNF levels [20]. In order to evaluate the effect of a long-term, 8 weeks partial social isolation on BDNF changes in hippocampus, the concentration of this neurotrophic factor was measured in the Sprague-Dawley rats placed in cages either single or in pairs [134]. Lower concentrations of the BDNF protein were present in the animals living in isolation. Reduction in the level of BDNF mRNA and protein after the chronic social isolation (social defeat stress) in rodents' hippocampus has also been reported by other authors $[156,177]$. A recent study by Viana Borges et al. [167] presenting a comparison of the effects of a social isolation (breeding in isolation) and a social support (breeding in pairs) on the level of BDNF in hippocampus of the Wistar rats additionally subjected to chronic unpredictable stress (CUS) confirmed the above-mentioned results. Furthermore, in animals subjected to isolation the decrease in the BDNF level in hippocampus was accompanied by the long-term memory impairment [167]. Therefore, higher expression of BDNF in animals living in social groups indicates the important role of this factor in stimulation of the mechanisms developing social relationships and maintaining mental health [35]. It has also been suggested that a social support may contribute to protecting against some effects of the stress-induced epigenetic modulation of BDNF genes [167]. This may be manifested by the preservation of cognitive functions. However, the detailed explanation of these regulatory mechanisms requires further research.

Predator odour. To assess reactions caused by fear of predators (predator scent stress), a test involving exposure of rodents to a smell of predator urine has been developed [80, 81]. After a single, short-term (10 $\mathrm{min}$ ) exposure to the stress factor, the level of BDNF mRNA in the CA1 sector of hippocampus was assessed 7 days after the exposure. Cat smell in- creased anxiety behaviour, which correlated with the long-term decline in BDNF mRNA [81]. It has been suggested that the action of the aforementioned stressor, via changes in BDNF expression, may lead to remodelling of the neuronal connections in hippocampus [81].

Chronic mild stress. In order to simulate unpredictable situations that may occur in the rodents environment, a model of chronic mild stress (CMS) was developed [170]. This model reflects many types of stimuli inducing anxiety behaviour. However, occasionally changes in physiological parameters and behavioural responses after its use are ambiguous. In hippocampus of the rats exposed to CMS an increase in the BDNF mRNA expression was reported, not a decrease, as it could be expected, despite a behavioural response resembling depression [85]. Other authors have reported reduced [78] or increased anxiety [77] after using this stress model. It has been suggested that this type of stressor affects emotional behaviour and, indirectly, also the activation of the HPA and the level of BDNF [110]. The substantial discrepancies in the results may be due to the interplay of different neurobiological variables. This means that various signalling pathways responsible for regulation of the BDNF expression may be activated, adapting the brain to different situational contexts and emotional states.

Osmotic stress. The sensitivity of the hypothalamic nuclei to the osmotic stimuli was the basis for elaboration of a test which is useful for detection of the BDNF protein and mRNA level changes $[4,6,28]$. Three and $4.5 \mathrm{~h}$ after intraperitoneal administration of $3 \mathrm{~mL}$ of hypertonic $1.35 \% \mathrm{NaCl}$ solution, an increase in the BDNF mRNA and BDNF protein concentration in the PVN and SON was reported in the Sprague-Dawley and Wistar rats $[4,6,28]$. The obtained results suggest the existence of a mechanism regulating the BDNF content, associated with sensitive to the osmotic stimuli areas located in hypothalamus.

Forced swimming. There is a documented evidence that the FS is responsible for inducing compensatory homeostatic mechanisms to prevent or reduce cytokine activation during a stress response $[115,117]$. Although mechanisms of such reactions are not completely understood, there are premises indicating that neurotransmitter systems (e.g. glutamatergic or monoaminergic) as well as the HPA axis are involved $[115,117]$. Interestingly, studies showed that both a single (20 $\mathrm{min}$ ) and a chronic (20 min/21 day) FS episodes did not cause changes in 
the density of BDNF-ir neurons in the PVN and SON nuclei in hypothalamus of the adult Wistar rats [12]. One can assume that the relatively low harmfulness of the applied stimulus could have prevented changes in the density of BDNF-ir neurons.

High light-open field stress. HL-OF is a relatively strong stressor which may initiate structural and functional changes in several brain areas $[64,118]$. The numerical density of BDNF-ir neurons in the PVN and SON was analysed in the Wistar rats undergoing $\mathrm{HL}-\mathrm{OF}$ [12]. After a single 20 min exposure to $\mathrm{HL}-\mathrm{OF}$, an increase in BDNF-ir in the SON was observed, which most likely was related to an increase in the level of neurohormones (e.g. AVP), synthesized depending on the HPA axis activity. However, the long-term 21-day stimulation with HL-OF did not affect the density of BDNF-ir neurons. One can presume that the activity of the HPA was not maintained at a sufficiently high level for such a long period of time or that the experimental animals adapted to this type of stressor.

\section{Aging}

It is commonly accepted that animal's response to stress changes with age $[93,115]$. Aging is a life period related with apparent changes of many functions of the limbic system and the neuroendocrine activity $[112,115]$. One of the consequences of aging is an increased lability of the HPA, which can lead to changes in its activation $[22,103,115]$. This is due to an impairment of the controlling the stress response mechanisms regulating the HPA activity which involve several brain structures, among which the most important are hypothalamus, hippocampus, and amygdala [115, 144, 146]. All this limits the ability to response adequately to stress $[112,115]$. The dysregulation of the system controlling stress response is manifested by a decreased inhibition of the HPA activity and termination of the stress response [57, 115].

An impairment of the negative feedback regulatory mechanisms of the HPA significantly modifies the action of glucocorticoids and their receptors [115]. It also influences the stress-dependent synthesis and secretion of the other neurohormones such as catecholamines [14, 93, 129], and increases the neuronal sensitivity to apoptosis [30, 131]. Importantly, during aging a stronger stimulus is required to induce a stress response, which in some cases may even increase the intensity of the reaction [112]. Finally, there are compensatory mechanisms activated during aging that enable adaptation to changing environmental conditions [56]. Activation of systems involved in the stress response was observed even in the absence of the stressor, which could be regarded as a state of readiness [56].

Immobilisation and chronic mild stress. Data about changes in BDNF expression in aging animals under influence of a mild stressor is still incomplete. Immobilisation reduced BDNF expression in hippocampus in older rodents [149]. This effect was present both after short- and long-term immobilisation. In the 24 month-old Fischer 344/N rats, a decrease in the BDNF mRNA in the DG was observed immediately after $2 \mathrm{~h}$ immobilisation [149]. The chronic immobilisation ( $2 \mathrm{~h} / 7$ days) reduced the BDNF mRNA in hippocampus in old (24 month) male Fischer 344/N rats [148].

A CUS model has been used to evaluate changes in BDNF expression in hippocampus [88, 142]. After an exposure of different duration (up to 28 days) on chronic unpredictable mild stress, a decrease in the BDNF mRNA expression in hippocampus was reported in the 22-month-old Sprague-Dawley rats [142]. Similarly, a 3-week exposure to CUS induced a decreased expression of BDNF in the hippocampal CA3 and DG in the 15-month-old Wistars [88]. A mild stress-induced decrease in BDNF expression in the hippocampal neurons is of a particular importance due to enhancement of changes in cognitive functions, learning, and memory during aging [1]. They could be a result of the impaired long-term synaptic enhancement observed at this stage of ontogenesis $[8,75]$. Less effective synaptic transmission prevents repeated neuronal stimulation which, in turn, may result in receptor desensitization and finally, prevents neuronal damage [154]. This process can be regarded as one of the positive compensatory mechanisms preventing structural and functional damage in the CNS during aging.

Forced swimming. The FS is useful for assessing changes in BDNF expression during aging. A shortterm stressor of $10 \mathrm{~min}$ swimming in cold water at $4^{\circ} \mathrm{C}$ induced a rapid increase in BDNF and the BDNF mRNA in hippocampus in the 22-month-old Sprague-Dawley rats, already $15 \mathrm{~min}$ after its completion [143]. A long-term $\mathrm{FS}$ of $10 \mathrm{~min}$ for 21 days in $25^{\circ} \mathrm{C}$ water reduced expression of the BDNF mRNA and protein after $60 \mathrm{~min}$ [143]. FS stimulation was also used to assess changes in the density of BDNF-ir neurons of the hippocampal pyramidal cell layer of CA1, CA3, and granular neurons in DG, and in the PVN and 
SON nuclei of hypothalamus in P360 and P720 Wistar rats [11-13,53]. After 20 min FS, an increase in the density of BDNF-ir neurons in CA2 and CA3 sectors of hippocampus was reported in the aged animals (P720) [11]. However, no difference was observed in the density of BDNF-ir neurons after exposure to chronic FS of $20 \mathrm{~min} / 21$ days in P360 and P720 age groups compared to the control groups [11-13,53]. The explanation of these results may provide a hypothesis assuming that the increase in expression of neurotrophins, including BDNF, after a short-term stress may be associated with the consolidation of information about a harmless event in order to prepare the future response to a new stressful stimulus [95]. The lack of increase in BDNF expression after prolonged stimulation with a harmless stimulus can be also explained by habituation.

High light-open field stress. An effect of stimulation with the HL-OF stressor on the density of BDNF-ir neurons was assessed in the pyramidal cell layer in the CA1, CA2, CA3 sectors of hippocampus, granule cells layer in the DG, and in the PVN and SON nuclei of hypothalamus in the Wistar rats $[11,12,53]$. While after exposure to an acute 20 min stress the density of BDNF-ir neurons increased in CA1-CA3 regions of hippocampus, it decreased in the PVN in P720 [11, 12]. However, a chronic 21-day HL-OF stimulation did not change the density of BDNF-ir neurons in the examined brain structures in both P360 and P720 $[11,12,53]$.

The increase in the density of BDNF-ir neurons after a single HL-OF stressor stimulation can be explained by the change in the HPA activation leading to the raised release of neurohormones. Interesting$l y$, the increase in the BDNF-ir density of pyramidal neurons after the short-term stressor exposure may stimulate memory in the aged animals [135]. The above-mentioned "state of readiness" or alert, may be responsible for prevention of the reduction in BDNF level after the chronic stress in the older animals [56]. The repeated exposure to the same stressor may also cause habituation [88].

\section{CONCLUSIONS}

Although almost each stressor is believed to increase the activity of the HPA, the response of neurons to individual stressors varies considerably. This may result from the number of involved neurotransmitters, neurohormones and neurotrophic factors, including BDNF. Based on the presented data, one can conclude that the effect of stressful stimuli on BDNF expression in the various brain areas at the specific stages of the ontogenetic development depends on several factors, such as species and genotypic characteristics of experimental animals, and their individual resistance to stress. In addition, the psychophysical condition seems to be of great importance, as it determines the way of coping with the stressful situations. Important factors to consider that may affect the results of research on stress mechanisms are: a type of stressor used, an experimental model of stress, an analysed brain area, the precision of the BDNF detection method, time of assessment of the neurotrophin level after stress stimulation, the tested form of neurotrophin (precursor or mature form of BDNF) and, finally, the BDNF mRNA level. The presented data, on the one hand, indicate participation of BDNF in response to a wide range of stressors. On the other hand, they point to a different dynamics of changes in this neurotrophin level, depending on the type of stressor and the stage of ontogenetic development. Results of the studies using various experimental stress models indicate the multidirectional effect of BDNF on shaping the response to stress. Further studies are warranted to better understand the role of this neutrophin in the CNS during a stress response, and to consider its potential use in designing new, effective strategies of stress prevention or treatment.

\section{Funding}

This research was supported by funds provided by the Polish Ministry of Science and Higher Education (ST-11).

\section{Conflict of interest: None declared}

\section{REFERENCES}

1. Adlard PA, Engesser-Cesar C, Cotman CW. Mild stress facilitates learning and exercise improves retention in aged mice. Exp Gerontol. 2011; 46(1): 53-59, doi: 10.1016/j. exger.2010.10.001, indexed in Pubmed: 20951791.

2. Aisa B, Tordera R, Lasheras B, et al. Cognitive impairment associated to HPA axis hyperactivity after maternal separation in rats. Psychoneuroendocrinology. 2007; 32(3): 256-266, doi: 10.1016/j.psyneuen.2006.12.013.

3. Alfonso J, Frick LR, Silberman DM, et al. Regulation of hippocampal gene expression is conserved in two species subjected to different stressors and antidepressant treatments. Biol Psychiatry. 2006; 59(3): 244-251, doi: 10.1016/j. biopsych.2005.06.036, indexed in Pubmed: 16140276.

4. Aliaga E, Arancibia S, Givalois L, et al. Osmotic stress increases brain-derived neurotrophic factor messenger RNA expression in the hypothalamic supraoptic nucleus 
with differential regulation of its transcripts. Relation to arginine-vasopressin content. Neuroscience. 2002; 112(4): 841-850, doi: 10.1016/s0306-4522(02)00128-8.

5. Allen S, Watson J, Shoemark D, et al. GDNF, NGF and BDNF as therapeutic options for neurodegeneration. Pharmacol Ther. 2013; 138(2): 155-175, doi: 10.1016/j. pharmthera.2013.01.004.

6. Arancibia S, Lecomte A, Silhol M, et al. In vivo brain-derived neurotrophic factor release and tyrosine kinase $B$ receptor expression in the supraoptic nucleus after osmotic stress stimulus in rats. Neuroscience. 2007; 146(2): 864-873, doi: 10.1016/j.neuroscience.2007.01.057, indexed in Pubmed: 17346893.

7. Arancibia $S$, Silhol M, Moulière $F$, et al. Protective effect of BDNF against beta-amyloid induced neurotoxicity in vitro and in vivo in rats. Neurobiol Dis. 2008; 31(3): 316-326, doi: 10.1016/j.nbd.2008.05.012S0969-9961(08)00099-5, indexed in Pubmed: 18585459.

8. Artola A, von Frijtag JC, Fermont PCJ, et al. Long-lasting modulation of the induction of LTD and LTP in rat hippocampal CA1 by behavioural stress and environmental enrichment. Eur J Neurosci. 2006; 23(1): 261-272, doi: 10.1111/j.1460-9568.2005.04552.x, indexed in Pubmed: 16420435.

9. Avital A, Richter-Levin G. Exposure to juvenile stress exacerbates the behavioural consequences of exposure to stress in the adult rat. Int J Neuropsychopharmacol. 2005; 8(2): 163-173, doi: 10.1017/S1461145704004808, indexed in Pubmed: 15546500.

10. Avitsur R, Stark J, Dhabhar F, et al. Social disruption-induced glucocorticoid resistance: kinetics and site specificity. J Neuroimmunol. 2002; 124(1-2): 54-61, doi: 10.1016/ s0165-5728(02)00010-3, indexed in Pubmed: 11958822.

11. BadowskaSzalewska E, Ludkiewicz B, Krawczyk R, et al. Comparison of the influence of two models of mild stress on hippocampal brainderived neurotrophin factor (BDNF) immunoreactivity in old age rats. Acta Neurobiologiae Experimentalis. 2017; 77(1): 68-76, doi: 10.21307/ane2017-037, indexed in Pubmed: 28379217.

12. Badowska-Szalewska E, Ludkiewicz B, Krawczyk R, et al. Exposure to mild stress and brain derived neurotrophin factor (BDNF) immunoreactivity in the hypothalamic paraventricular (PVN) and supraoptic (SON) nuclei: Comparison between aged and adult rats. J Chem Neuroanat. 2016; 78: 57-64, doi: 10.1016/j.jchemneu.2016.08.007, indexed in Pubmed: 27565677.

13. Badowska-Szalewska E, Spodnik E, Klejbor I, et al. Effects of chronic forced swim stress on hippocampal brain-derived neutrophic factor (BDNF) and its receptor (TrkB) immunoreactive cells in juvenile and aged rats. Acta Neurobiol Exp. 2010; 70(4): 370-381, indexed in Pubmed: 21196945.

14. Bahtiyar S, Karaca KG, Henckens M, et al. Norepinephrine and glucocorticoid effects on the brain mechanisms underlying memory accuracy and generalization. Mol Cell Neurosci. 2020; 108: 103537, doi: 10.1016/j. mcn.2020.103537, indexed in Pubmed: 32805389.

15. Bale TL, Vale WW. CRF and CRF receptors: role in stress responsivity and other behaviors. Annu Rev Pharmacol Toxicol. 2004; 44: 525-557, doi: 10.1146/annurev.pharmtox.44.101802.121410, indexed in Pubmed: 14744257.

16. Barbany $G$, Persson $H$. Regulation of neurotrophin mRNA expression in the rat brain by glucocorticoids. Eur J Neuro- sci. 1992; 4(5): 396-403, doi: 10.1111/j.1460-9568.1992. tb00888.x, indexed in Pubmed: 12106347.

17. Barrientos RM, Sprunger DB, Campeau S, et al. Brain-derived neurotrophic factor mRNA downregulation produced by social isolation is blocked by intrahippocampal interleukin-1 receptor antagonist. Neuroscience. 2003; 121(4): 847-853, doi: 10.1016/s0306-4522(03)00564-5, indexed in Pubmed: 14580934.

18. Bazak N, Kozlovsky N, Kaplan Z, et al. Pre-pubertal stress exposure affects adult behavioral response in association with changes in circulating corticosterone and brain-derived neurotrophic factor. Psychoneuroendocrinology. 2009; 34(6): 844-858, doi: 10.1016/j. psyneuen.2008.12.018, indexed in Pubmed: 19181453.

19. Bennett MR, Lagopoulos J. Stress and trauma: BDNF control of dendritic-spine formation and regression. Prog Neurobiol. 2014; 112: 80-99, doi: 10.1016/j.pneurobio.2013.10.005, indexed in Pubmed: 24211850.

20. Berry A, Bellisario V, Capoccia S, et al. Social deprivation stress is a triggering factor for the emergence of anxiety- and depression-like behaviours and leads to reduced brain BDNF levels in C57BL/6J mice. Psychoneuroendocrinology. 2012; 37(6): 762-772, doi: 10.1016/j. psyneuen.2011.09.007, indexed in Pubmed: 21974975.

21. Biggio F, Pisu MG, Garau A, et al. Maternal separation attenuates the effect of adolescent social isolation on HPA axis responsiveness in adult rats. Eur Neuropsychopharmacol. 2014; 24(7): 1152-1161, doi: 10.1016/j. euroneuro.2014.03.009.

22. Boguszewski P, Zagrodzka J. Emotional changes related to age in rats: a behavioral analysis. Behav Brain Res. 2002; 133(2): 323-332, doi: 10.1016/s0166-4328(02)00018-9, indexed in Pubmed: 12110466.

23. Brunson KL, Khan N, Eghbal-Ahmadi M, et al. Corticotropin (ACTH) acts directly on amygdala neurons to down-regulate corticotropin-releasing hormone gene expression. Ann Neurol. 2001; 49(3): 304-312, indexed in Pubmed: 11261504.

24. Caldji C, Diorio J, Meaney M. Variations in maternal care in infancy regulate the development of stress reactivity. Biol Psychiatry. 2000; 48(12): 1164-1174, doi: 10.1016/ s0006-3223(00)01084-2.

25. Capoccia S, Berry A, Bellisario V, et al. Quality and timing of stressors differentially impact on brain plasticity and neuroendocrine-immune function in mice. Neural Plast. 2013; 2013(971817), doi: 10.1155/2013/971817, indexed in Pubmed: 23606988.

26. Carrasco G, Van de Kar LD. Neuroendocrine pharmacology of stress. Eur J Pharmacol. 2003; 463(1-3): 235-272, doi: 10.1016/s0014-2999(03)01285-8, indexed in Pubmed: 12600714.

27. Castrén E, Kojima M. Brain-derived neurotrophic factor in mood disorders and antidepressant treatments. Neurobiol Dis. 2017; 97(Pt B): 119-126, doi: 10.1016/j. nbd.2016.07.010, indexed in Pubmed: 27425886.

28. Castren $E$, Thoenen $H$, Lindholm D. Brain-derived neurotrophic factor messenger RNA is expressed in the septum, hypothalamus and in adrenergic brain stem nuclei of adult rat brain and is increased by osmotic stimulation in the paraventricular nucleus. Neuroscience. 1995; 64(1): 71-80, doi: 10.1016/0306-4522(94)00386-j, indexed in Pubmed: 7708216.

29. Chen M, He G, Li Q. Maternal deprivation promotes hippocampal neuronal apoptosis via ERK1/2 signaling. 
Front Biosci (Landmark Ed). 2018; 23: 1923-1932, doi: 10.2741/4681, indexed in Pubmed: 29772537.

30. Chen TT, Maevsky El, Uchitel ML. Maintenance of homeostasis in the aging hypothalamus: the central and peripheral roles of succinate. Front Endocrinol (Lausanne). 2015; 6: 7, doi: 10.3389/fendo.2015.00007, indexed in Pubmed: 25699017.

31. Cheng A, Wang S, Cai J, et al. Nitric oxide acts in a positive feedback loop with BDNF to regulate neural progenitor cell proliferation and differentiation in the mammalian brain. Dev Biol. 2003; 258(2): 319-333, doi: 10.1016/ s0012-1606(03)00120-9, indexed in Pubmed: 12798291.

32. Chiba $S$, Numakawa T, Ninomiya M, et al. Chronic restraint stress causes anxiety- and depression-like behaviors, downregulates glucocorticoid receptor expression, and attenuates glutamate release induced by brain-derived neurotrophic factor in the prefrontal cortex. Prog Neuropsychopharmacol Biol Psychiatry. 2012; 39(1): 112-119, doi: 10.1016/j.pnpbp.2012.05.018, indexed in Pubmed: 22664354.

33. Choy KH, de Visser Y, Nichols NR, et al. Combined neonatal stress and young-adult glucocorticoid stimulation in rats reduce BDNF expression in hippocampus: effects on learning and memory. Hippocampus. 2008; 18(7): 655-667, doi: 10.1002/hipo.20425, indexed in Pubmed: 18398848.

34. Chung EKY, Bian ZX, Xu HX, et al. Neonatal maternal separation increases brain-derived neurotrophic factor and tyrosine kinase receptor $B$ expression in the descending pain modulatory system. Neurosignals. 2009; 17(3): 213-221, doi: 10.1159/000224631, indexed in Pubmed: 19546592.

35. Cirulli F, Berry A, Bonsignore LT, et al. Early life influences on emotional reactivity: evidence that social enrichment has greater effects than handling on anxiety-like behaviors, neuroendocrine responses to stress and central BDNF levels. Neurosci Biobehav Rev. 2010; 34(6): 808-820, doi: 10.1016/j.neubiorev.2010.02.008, indexed in Pubmed: 20171244.

36. Cohen H, Kaplan Z, Matar MA, et al. Long-lasting behavioral effects of juvenile trauma in an animal model of PTSD associated with a failure of the autonomic nervous system to recover. Eur Neuropsychopharmacol. 2007; 17(6-7): 464-477, doi: 10.1016/j.euroneuro.2006.11.003, indexed in Pubmed: 17196373.

37. Cowansage KK, LeDoux JE, Monfils MH. Brain-derived neurotrophic factor: a dynamic gatekeeper of neural plasticity. Curr Mol Pharmacol. 2010; 3(1): 12-29, do i: $10.2174 / 1874467211003010012$, indexed in Pubmed: 20030625.

38. Cunha C, Brambilla R, Thomas KL. A simple role for BDNF in learning and memory? Front Mol Neurosci. 2010; 3: 1, doi: 10.3389/neuro.02.001.2010, indexed in Pubmed: 20162032.

39. Abdissa D, Hamba N, Gerbi A. Review Article on adult neurogenesis in humans. Translational Research in Anatomy. 2020; 20: 100074, doi: 10.1016/j.tria.2020.100074.

40. Dal-Zotto S, Martı O, Armario A. Influence of single or repeated experience of rats with forced swimming on behavioural and physiological responses to the stressor. Beh Brain Res. 2000; 114(1-2): 175-181, doi: 10.1016/s0166-4328(00)00220-5, indexed in Pubmed: 10996058.

41. Daskalakis N, Kloet ED, Yehuda R, et al. Early life stress effects on glucocorticoid-BDNF interplay in the hip- pocampus. Front Mol Neurosci. 2015; 8, doi: 10.3389/ fnmol.2015.00068, indexed in Pubmed: 26635521.

42. Dayas CV, Buller KM, Crane JW, et al. Stressor categorization: acute physical and psychological stressors elicit distinctive recruitment patterns in the amygdala and in medullary noradrenergic cell groups. Eur J Neurosci. 2001; 14(7): 1143-1152, doi: 10.1046/j.0953816x.2001.01733.x, indexed in Pubmed: 11683906.

43. de Kloet ER, Sibug RM, Helmerhost FM, et al. Stress, genes and the mechanism of programming the brain for later life. Neurosci Biobehav Rev. 2005; 29(2): 271-281, doi: 10.1016/j.neubiorev.2004.10.008, indexed in Pubmed: 15811498.

44. Dent G, Choi DC, Herman JP, et al. GABAergic circuits and the stress hyporesponsive period in the rat: ontogeny of glutamic acid decarboxylase (GAD) 67 mRNA expression in limbic-hypothalamic stress pathways. Brain Res. 2007; 1138: 1-9, doi: 10.1016/j.brainres.2006.04.082, indexed in Pubmed: 17276416.

45. Dimatelis JJ, Russell VA, Stein DJ, et al. Methamphetamine reversed maternal separation-induced decrease in nerve growth factor in the ventral hippocampus. Metab Brain Dis. 2014; 29(2): 433-439, doi: 10.1007/s11011-0149481-z, indexed in Pubmed: 24407463.

46. Dubovicky M, Jezova D. Effect of chronic emotional stress on habituation processes in open field in adult rats. Ann N Y Acad Sci. 2004; 1018: 199-206, doi: 10.1196/ annals.1296.023, indexed in Pubmed: 15240369.

47. Duman RS, Malberg J, Nakagawa S. Regulation of adult neurogenesis by psychotropic drugs and stress. J Pharmacol Exp Ther. 2001; 299(2): 401-407, indexed in Pubmed: 11602648.

48. Dwivedi Y, Rizavi HS, Pandey GN. Antidepressants reverse corticosterone-mediated decrease in brain-derived neurotrophic factor expression: differential regulation of specific exons by antidepressants and corticosterone. Neuroscience. 2006; 139(3): 1017-1029, doi: 10.1016/j.neuroscience.2005.12.058, indexed in Pubmed: 16500030.

49. Eisch A. Adult neurogenesis: implications for psychiatry. Prog Brain Res. 2002: 315-342, doi: 10.1016/s00796123(02)38085-3, indexed in Pubmed: 12432777.

50. Eisch AJ, Barrot M, Schad CA, et al. Opiates inhibit neurogenesis in the adult rat hippocampus. Proc Natl Acad Sci U S A. 2000; 97(13): 7579-7584, doi: 10.1073/ pnas.120552597, indexed in Pubmed: 10840056.

51. Elliott E, Ezra-Nevo G, Regev L, et al. Resilience to social stress coincides with functional DNA methylation of the Crf gene in adult mice. Nature Neuroscience. 2010; 13(11): 1351-1353, doi: 10.1038/nn.2642, indexed in Pubmed: 20890295.

52. Engelmann M, Ludwig M. The activity of the hypothalamo-neurohypophysial system in response to acute stressor exposure: neuroendocrine and electrophysiological observations. Stress. 2004; 7(2): 91-96, doi: 10.1080/1 0253890410001677240 , indexed in Pubmed: 15512852.

53. Ewa BS, Beata L, llona K, et al. Brain derived neurotrophic factor (BDNF) containing neurons in the hypothalamic paraventricular and supraoptic nuclei of juvenile and middle-aged rats after chronic stress. Int J Dev Neurosci. 2012; 30(2): 139-146, doi: 10.1016/j. ijdevneu.2011.12.001, indexed in Pubmed: 22178659.

54. Farrell C, O'Keane V. Epigenetics and the glucocorticoid receptor: A review of the implications in depression. 
Psychiatry Res. 2016; 242: 349-356, doi: 10.1016/j. psychres.2016.06.022, indexed in Pubmed: 27344028.

55. Fenoglio KA, Brunson KL, Baram TZ. Hippocampal neuroplasticity induced by early-life stress: functional and molecular aspects. Front Neuroendocrinol. 2006; 27(2): 180-192, doi: 10.1016/j.yfrne.2006.02.001, indexed in Pubmed: 16603235.

56. Frolkis V. Stress-age syndrome. Mech Ageing Dev. 1993; 69(1-2): 93-107, doi: 10.1016/0047-6374(93)90074-2, indexed in Pubmed: 8104261.

57. Gilad G, Gilad V. Strain, stress, neurodegeneration and longevity. Mech Ageing Dev. 1995; 78(2): 75-83, doi: 10.1016/0047-6374(94)01529-u, indexed in Pubmed: 7596198.

58. Givalois L, Naert G, Rage F, et al. A single brain-derived neurotrophic factor injection modifies hypothalamo-pituitary-adrenocortical axis activity in adult male rats. Mol Cell Neurosci. 2004; 27(3): 280-295, doi: 10.1016/j. mcn.2004.07.002, indexed in Pubmed: 15519243.

59. Goldman L, Winget C, Hollingshead GW, et al. Postweaning development of negative feedback in the pituitary-adrenal system of the rat. Neuroendocrinology. 1973; 12(3): 199-211, doi: 10.1159/000122169, indexed in Pubmed: 4353346.

60. Gray JD, Milner TA, McEwen BS. Dynamic plasticity: the role of glucocorticoids, brain-derived neurotrophic factor and other trophic factors. Neuroscience. 2013; 239: 214-227, doi: 10.1016/j.neuroscience.2012.08.034, indexed in Pubmed: 22922121.

61. Greenberg $M E, X u B, L u B$, et al. New insights in the biology of BDNF synthesis and release: implications in CNS function. J Neurosci. 2009; 29(41): 12764-12767, doi: 10.1523/JNEUROSCI.3566-09.2009, indexed in Pubmed: 19828787.

62. Greisen MH, Altar CA, Bolwing TG, et al. Increased adult hippocampal brain-derived neurotrophic factor and normal levels of neurogenesis in maternal separation rats. J Neurosci Res. 2005; 79(6): 772-778, doi: 10.1002/ jnr.20418, indexed in Pubmed: 15690366.

63. Groves JO. Is it time to reassess the BDNF hypothesis of depression? Mol Psychiatry. 2007; 12(12): 1079-1088, doi: $10.1038 /$ sj.mp.4002075, indexed in Pubmed: 17700574.

64. Hale MW, Bouwknecht JA, Spiga F, et al. Exposure to high- and low-light conditions in an open-field test of anxiety increases c-Fos expression in specific subdivisions of the rat basolateral amygdaloid complex. Brain Res Bull. 2006; 71(1-3): 174-182, doi: 10.1016/j.brainresbull.2006.09.001, indexed in Pubmed: 17113944.

65. Heese $K$, Otten $U$, Mathivet $P$, et al. GABAB receptor antagonists elevate both mRNA and protein levels of the neurotrophins nerve growth factor (NGF) and brain-derived neurotrophic factor (BDNF) but not neurotrophin-3 (NT-3) in brain and spinal cord of rats. Neuropharmacology. 2000; 39(3): 449-462, doi: 10.1016/ s0028-3908(99)00166-5, indexed in Pubmed: 10698011.

66. Heidbreder CA, Weiss IC, Domeney AM, et al. Behavioral, neurochemical and endocrinological characterization of the early social isolation syndrome. Neuroscience. 2000; 100(4): 749-768, doi: 10.1016/s0306-4522(00)00336-5, indexed in Pubmed: 11036209.

67. Herman JP, Figuieredo H, Mueller NK. Central mechanisms of stress integration: hierarchical circuitry controlling hy- pothalamo-pituitary-adrenocortical responsiveness. Front Neuroendocrinol. 2003; 24(3): 151-158, doi: 10.1016/j. yfrne.2003.07.001, indexed in Pubmed: 14596810.

68. Herman J, McKlveen J, Ghosal S, et al. Regulation of the hypothalamic pituitary adrenocortical stress response. Compr Physiol. 2016; 6(2): 603-621, doi: 10.1002/cphy. c150015, indexed in Pubmed: 27065163.

69. Herman J, Ostrander M, Mueller N, et al. Limbic system mechanisms of stress regulation: Hypothalamo-pituitary-adrenocortical axis. Prog Neuropsychopharmacol Biol Psychiatry. 2005; 29(8): 1201-1213, doi: 10.1016/j. pnpbp.2005.08.006, indexed in Pubmed: 16271821.

70. Huot R, Plotsky $P$, Lenox $R$, et al. Neonatal maternal separation reduces hippocampal mossy fiber density in adult Long Evans rats. Brain Res. 2002; 950(1-2): 52-63, doi: 10.1016/s0006-8993(02)02985-2, indexed in Pubmed: 12231228.

71. Jeanneteau F, Chao MV. Are BDNF and glucocorticoid activities calibrated? Neuroscience. 2013; 239: 173-195, doi: 10.1016/j.neuroscience.2012.09.017, indexed in Pubmed: 23022538.

72. Jeanneteau F, Garabedian MJ, Chao MV. Activation of Trk neurotrophin receptors by glucocorticoids provides a neuroprotective effect. Proc Natl Acad Sci U S A. 2008; 105(12): 4862-4867, doi: 10.1073/pnas.0709102105, indexed in Pubmed: 18347336.

73. Jeanneteau, FD, Lambert WM, Ismaili M, et al. DNF and glucocorticoids regulate corticotrophin-releasing hormone (CRH) homeostasis in the hypothalamus. Proc Natl Acad Sci U S A. 2012; 109(4): 1305-1310, doi: 10.1073/ pnas.1114122109, indexed in Pubmed: 22232675.

74. Joëls $M$, Karst $H$, Alfarez $D$, et al. Effects of chronic stress on structure and cell function in rat hippocampus and hypothalamus. Stress. 2004; 7(4): 221-231, doi: 10.1080/10253890500070005, indexed in Pubmed: 16019587.

75. Kim JJ, Diamond DM. The stressed hippocampus, synaptic plasticity and lost memories. Nat Rev Neurosci. 2002; 3(6): 453-462, doi: 10.1038/nrn849, indexed in Pubmed: 12042880.

76. Knipper M, da Penha Berzaghi M, Blöchl A, et al. Positive feedback between acetylcholine and the neurotrophins nerve growth factor and brain-derived neurotrophic factor in the rat hippocampus. Eur J Neurosci. 1994; 6(4): 668-671, doi: 10.1111/j.1460-9568.1994.tb00312.x, indexed in Pubmed: 8025717.

77. Kompagne H, Bárdos G, Szénási G, et al. Chronic mild stress generates clear depressive but ambiguous anxiety-like behaviour in rats. Behav Brain Res. 2008; 193(2): 311-314, doi: 10.1016/j.bbr.2008.06.008, indexed in Pubmed: 18590771.

78. Kopp C, Vogel E, Rettori MC, et al. The effects of melatonin on the behavioural disturbances induced by chronic mild stress in C3H/He mice. Behav Pharmacol. 1999; 10(1): 73-83, doi: 10.1097/00008877-199902000-00007, indexed in Pubmed: 10780304.

79. Kowiański P, Lietzau G, Czuba E, et al. BDNF: A Key Factor with Multipotent Impact on Brain Signaling and Synaptic Plasticity. Cel Mol Neurobiol. 2017; 38(3): 579-593, doi: 10.1007/s10571-017-0510-4, indexed in Pubmed: 28623429

80. Kozlovsky N, Kaplan Z, Zohar J, et al. Protein synthesis inhibition before or after stress exposure results in divergent 
endocrine and BDNF responses disassociated from behavioral responses. Depress Anxiety. 2008; 25(5): E24-E34, doi: 10.1002/da.20366, indexed in Pubmed: 17828750.

81. Kozlovsky N, Matar MA, Kaplan Z, et al. Long-term down-regulation of BDNF mRNA in rat hippocampal CA1 subregion correlates with PTSD-like behavioural stress response. Int J Neuropsychopharmacol. 2007; 10(6): 741-758, doi: 10.1017/S1461145707007560, indexed in Pubmed: 17291374.

82. Krishnan V, Nestler EJ. The molecular neurobiology of depression. Nature. 2008; 455(7215): 894-902, doi: 10.1038/ nature07455, indexed in Pubmed: 18923511.

83. Kuma H, Miki T, Matsumoto $Y$, et al. Early maternal deprivation induces alterations in brain-derived neurotrophic factor expression in the developing rat hippocampus. Neurosci Lett. 2004; 372(1-2): 68-73, doi: 10.1016/j. neulet.2004.09.012, indexed in Pubmed: 15531090.

84. Lakshminarasimhan $\mathrm{H}$, Chattarji $\mathrm{S}$. Stress leads to contrasting effects on the levels of brain derived neurotrophic factor in the hippocampus and amygdala. PLoS One. 2012; 7(1): e30481, doi: 10.1371/journal.pone.0030481, indexed in Pubmed: 22272355.

85. Larsen MH, Mikkelsen JD, Hay-Schmidt A, et al. Regulation of brain-derived neurotrophic factor (BDNF) in the chronic unpredictable stress rat model and the effects of chronic antidepressant treatment. J Psychiatr Res. 2010; 44(13): 808-816, doi: 10.1016/j.jpsychires.2010.01.005, indexed in Pubmed: 20172535.

86. Lee RS, Sawa A. Environmental stressors and epigenetic control of the hypothalamic-pituitary-adrenal axis. Neuroendocrinology. 2014; 100(4): 278-287, doi: 10.1159/000369585, indexed in Pubmed: 25427939.

87. Levine S, Huchton DM, Wiener SG, et al. Time course of the effect of maternal deprivation on the hypothalamic-pituitary-adrenal axis in the infant rat. Dev Psychobiol. 1991; 24(8): 547-558, doi: 10.1002/dev.420240803, indexed in Pubmed: 1773913.

88. Li $Y$, Ji $Y$, Jiang $H$, et al. Effects of unpredictable chronic stress on behavior and brain-derived neurotrophic factor expression in CA3 subfield and dentate gyrus of the hippocampus in different aged rats. Chin Med J (Engl). 2009; 122(13): 1564-1569, indexed in Pubmed: 19719949.

89. Lindvall $\mathrm{O}$, Kokaia Z, Bengzon J, et al. Neurotrophins and brain insults. Trends Neurosci. 1994; 17(11): 490-496, doi: 10.1016/0166-2236(94)90139-2, indexed in Pubmed: 7531892.

90. Linz R, Puhlmann LMC, Apostolakou F, et al. Acute psychosocial stress increases serum BDNF levels: an antagonistic relation to cortisol but no group differences after mental training. Neuropsychopharmacology. 2019; 44(10): 1797-1804, doi: 10.1038/s41386-019-0391-y, indexed in Pubmed: 30991416.

91. Lopez JP, Mamdani F, Labonte B, et al. Epigenetic regulation of BDNF expression according to antidepressant response. Mol Psychiatry. 2013; 18(4): 398-399, doi: $10.1038 / \mathrm{mp} .2012 .38 \mathrm{mp} 201238$, indexed in Pubmed: 22547115.

92. Lu B, Nagappan G, Guan X, et al. BDNF-based synaptic repair as a disease-modifying strategy for neurodegenerative diseases. Nature Rev Neurosci. 2013; 14(6): 401-416, doi: 10.1038/nrn3505, indexed in Pubmed: 23674053.

93. Lupien SJ, McEwen BS, Gunnar MR, et al. Effects of stress throughout the lifespan on the brain, behaviour and cogni- tion. Nat Rev Neurosci. 2009; 10(6): 434-445, doi: 10.1038/ nrn2639nrn2639, indexed in Pubmed: 19401723.

94. MacQueen G, Ramakrishnan K, Ratnasingan R, et al. Desipramine treatment reduces the long-term behavioural and neurochemical sequelae of early-life maternal separation. Int J Neuropsychopharmacol. 2003; 6(4): 391-396, doi: 10.1017/s1461145703003729, indexed in Pubmed: 14641986.

95. Marmigère $F$, Givalois $L$, Rage $F$, et al. Rapid induction of BDNF expression in the hippocampus during immobilization stress challenge in adult rats. Hippocampus. 2003; 13(5): 646-655, doi: 10.1002/hipo.10109, indexed in Pubmed: 12921353.

96. Marmigère $F$, Rage $F$, Tapia-Arancibia L. GABA-glutamate interaction in the control of BDNF expression in hypothalamic neurons. Neurochemistry International. 2003; 42(4): 353-358, doi: 10.1016/s0197-0186(02)00100-6, indexed in Pubmed: 12470709.

97. Marmigère $F$, Rage $F$, Tapia-Arancibia L. Regulation of brain-derived neurotrophic factor transcripts by neuronal activation in rat hypothalamic neurons. J Neurosci Res. 2001; 66(3): 377-389, doi: 10.1002/jnr.1230, indexed in Pubmed: 11746355 .

98. Mattson MP, Maudsley S, Martin B. BDNF and 5-HT: a dynamic duo in age-related neuronal plasticity and neurodegenerative disorders. Trends Neurosci. 2004; 27(10): 589-594, doi: 10.1016/j.tins.2004.08.001, indexed in Pubmed: 15374669.

99. McCormick C, Mathews I, Thomas C, et al. Investigations of HPA function and the enduring consequences of stressors in adolescence in animal models. Brain Cogn. 2010; 72(1): 73-85, doi: 10.1016/j.bandc.2009.06.003, indexed in Pubmed: 19616355.

100. McEwen BS. Central effects of stress hormones in health and disease: Understanding the protective and damaging effects of stress and stress mediators. Eur J Pharmacol. 2008; 583(2-3): 174-185, doi: 10.1016/j. ejphar.2007.11.071, indexed in Pubmed: 18282566.

101. McEwen B. Effects of adverse experiences for brain structure and function. Biol Psychiatry. 2000; 48(8): 721-731, doi: 10.1016/s0006-3223(00)00964-1, indexed in Pubmed: 11063969.

102. McEwen BS. Structural plasticity of the adult brain: how animal models help us understand brain changes in depression and systemic disorders related to depression. Dialogues Clin Neurosci. 2004; 6(2): 119-133, doi: 10.31887/DCNS.2004.6.2/bmcewen, indexed in Pubmed: 22034132.

103. Meyza KZ, Boguszewski PM, Nikolaev E, et al. The effect of age on the dynamics and the level of c-Fos activation in response to acute restraint in Lewis rats. Behav Brain Res. 2007; 180(2): 183-189, doi: 10.1016/j.bbr.2007.03.007, indexed in Pubmed: 17452054.

104. Miranda M, Morici J, Zanoni M, et al. Brain-Derived neurotrophic factor: a key molecule for memory in the healthy and the pathological brain. Front Cell Neurosci. 2019; 13: 363, doi: 10.3389/fncel.2019.00363, indexed in Pubmed: 31440144.

105. Miyata S, Itoh T, Matsushima O, et al. Not only osmotic stress but also repeated restraint stress causes structural plasticity in the supraoptic nucleus of the rat hypothalamus. Brain Res Bull. 1994; 33(6): 669-675, doi: 10.1016/03619230(94)90231-3, indexed in Pubmed: 8193921. 
106. Morrissey MD, Mathews IZ, McCormick CM. Enduring deficits in contextual and auditory fear conditioning after adolescent, not adult, social instability stress in male rats. Neurobiol Learn Mem. 2011; 95(1): 46-56, doi: 10.1016/j. nlm.2010.10.007, indexed in Pubmed: 20970512.

107. Murakami S, Imbe H, Morikawa Y, et al. Chronic stress, as well as acute stress, reduces BDNF mRNA expression in the rat hippocampus but less robustly. Neurosci Res. 2005; 53(2): 129-139, doi: 10.1016/j.neures.2005.06.008, indexed in Pubmed: 16024125.

108. Naert G, Ixart G, Maurice T, et al. Brain-derived neurotrophic factor and hypothalamic-pituitary-adrenal axis adaptation processes in a depressive-like state induced by chronic restraint stress. Mol Cell Neurosci. 2011; 46(1): 55-66, doi: 10.1016/j.mcn.2010.08.006, indexed in Pubmed: 20708081.

109. Naert G, Zussy C, Tran Van Ba C, et al. Involvement of endogenous brain-derived neurotrophic factor in hypothalamic-pituitary-adrenal axis activity. J Neuroendocrinol. 2015; 27(11): 850-860, doi: 10.1111/jne.12324, indexed in Pubmed: 26388293.

110. Nutt DJ, Stein DJ. Understanding the neurobiology of comorbidity in anxiety disorders. CNS Spectr. 2006; $11(10$ Suppl 12): 13-20, doi: 10.1017/s1092852900025803, indexed in Pubmed: 17008826.

111. Ohta KI, Suzuki S, Warita K, et al. Prolonged maternal separation attenuates BDNF-ERK signaling correlated with spine formation in the hippocampus during early brain development. J Neurochem. 2017; 141(2): 179-194, doi: 10.1111/jnc.13977, indexed in Pubmed: 28178750.

112. Pardon MC. Stress and ageing interactions: a paradox in the context of shared etiological and physiopathological processes. Brain Res Rev. 2007; 54(2): 251-273, doi: 10.1016/j. brainresrev.2007.02.007, indexed in Pubmed: 17408561.

113. Pardon MC, Roberts RE, Marsden CA, et al. Social threat and novel cage stress-induced sustained extracellular-regulated kinase1/2 (ERK1/2) phosphorylation but differential modulation of brain-derived neurotrophic factor (BDNF) expression in the hippocampus of NMRI mice. Neuroscience. 2005; 132(3): 561-574, doi: 10.1016/j.neuroscience.2005.01.033, indexed in Pubmed: 15837118.

114. Park C, Rosenblat J, Brietzke E, et al. Stress, epigenetics and depression: A systematic review. Neurosci Biobehav Rev. 2019; 102: 139-152, doi: 10.1016/j.neubiorev.2019.04.010, indexed in Pubmed: 31005627.

115. Pedersen WA, Wan R, Mattson MP, et al. Impact of aging on stress-responsive neuroendocrine systems. Mech Ageing Dev. 2001; 122(9): 963-983, doi: 10.1016/s00476374(01)00250-0, indexed in Pubmed: 11348661.

116. Pizarro J, Lumley L, Medina W, et al. Acute social defeat reduces neurotrophin expression in brain cortical and subcortical areas in mice. Brain Res. 2004; 1025(1-2): 10-20, doi: 10.1016/j.brainres.2004.06.085, indexed in Pubmed: 15464739.

117. Plata-Salaman CR, llyin SE, Turrin NP, et al. Neither acute nor chronic exposure to a naturalistic (predator) stressor influences the interleukin-1 beta system, tumor necrosis factor-alpha, transforming growth factor-beta1, and neuropeptide mRNAs in specific brain regions. Brain Res Bull. 2000; 51(12): 187-193, doi: 10.1016/s03619230(99)00204-x, indexed in Pubmed: 10709966.

118. Prut $L$, Belzung $C$. The open field as a paradigm to measure the effects of drugs on anxiety-like behaviors: a review.
Eur J Pharmacol. 2003; 463(1-3): 3-33, doi: 10.1016/ s0014-2999(03)01272-x, indexed in Pubmed: 12600700.

119. Rage $F$, Givalois L, Marmigère $F$, et al. Immobilization stress rapidly modulates BDNF mRNA expression in the hypothalamus of adult male rats. Neuroscience. 2002; 112(2): 309-318, doi: 10.1016/s0306-4522(02)00072-6, indexed in Pubmed: 12044449.

120. Ray B, Gaskins DL, Sajdyk TJ, et al. Restraint stress and repeated corticotrophin-releasing factor receptor activation in the amygdala both increase amyloid- precursor protein and amyloid- peptide but have divergent effects on brain-derived neurotrophic factor and pre-synaptic proteins in the prefrontal cortex of rats. Neuroscience. 2011; 184: 139-150, doi: 10.1016/j.neuroscience.2011.03.067, indexed in Pubmed: 21477639.

121. Reagan L, Hendry R, Reznikov L, et al. Tianeptine increases brain-derived neurotrophic factor expression in the rat amygdala. Eur J Pharmacol. 2007; 565(1-3): 68-75, doi: 10.1016/j.ejphar.2007.02.023, indexed in Pubmed: 17368617.

122. Récamier-Carballo S, Estrada-Camarena E, López-Rubalcava C. Maternal separation induces long-term effects on monoamines and brain-derived neurotrophic factor levels on the frontal cortex, amygdala, and hippocampus: differential effects after a stress challenge. Behav Pharmacol. 2017; 28(7): 545-557, doi: 10.1097/ FBP.0000000000000324, indexed in Pubmed: 28704274.

123. Reichardt LF. Neurotrophin-regulated signalling pathways. Philos Trans R Soc Lond B Biol Sci. 2006; 361(1473): 1545-1564, doi: 10.1098/rstb.2006.1894, indexed in Pubmed: 16939974.

124. Réus G, Stringari R, Ribeiro K, et al. Maternal Deprivation Induces Depressive-like Behaviour and Alters Neurotrophin Levels in the Rat Brain. Neurochem Res. 2010; 36(3): 460-466, doi: 10.1007/s11064-010-0364-3, indexed in Pubmed: 21161589.

125. Rinaman L. Postnatal development of catecholamine inputs to the paraventricular nucleus of the hypothalamus in rats. J Comp Neurol. 2001; 438(4): 411-422, doi: 10.1002/cne.1324, indexed in Pubmed: 11559897.

126. Roceri M, Cirulli F, Pessina C, et al. Postnatal repeated maternal deprivation produces age-dependent changes of brain-derived neurotrophic factor expression in selected rat brain regions. Biol Psychiatry. 2004; 55(7): 708-714, doi: 10.1016/j.biopsych.2003.12.011, indexed in Pubmed: 15038999.

127. Rosenbrock $H$, Koros E, Bloching A, et al. Effect of chronic intermittent restraint stress on hippocampal expression of marker proteins for synaptic plasticity and progenitor cell proliferation in rats. Brain Res. 2005; 1040(1-2): 55-63, doi: 10.1016/j.brainres.2005.01.065, indexed in Pubmed: 15804426

128. Rosenfeld P, Wetmore J, Levine S. Effects of repeated maternal separations on the adrenocortical response to stress of preweanling rats. Physiol Behav. 1992; 52(4): 787-791, doi: 10.1016/0031-9384(92)90415-x, indexed in Pubmed: 1409954.

129. Rosenzweig E, Barnes C. Impact of aging on hippocampal function: plasticity, network dynamics, and cognition. Prog Neurobiol. 2003; 69(3): 143-179, doi: 10.1016/ s0301-0082(02)00126-0, indexed in Pubmed: 12758108.

130. Roth TL, Lubin FD, Funk $A J$, et al. asting epigenetic influence of early-life adversity on the BDNF gene. 
Biol Psychiatry. 2009; 65(9): 760-769, doi: 10.1016/j. biopsych.2008.11.028, indexed in Pubmed: 19150054.

131. Sapolsky R, Krey L, McEwen B. The adrenocortical axis in the aged rat: Impaired sensitivity to both fast and delayed feedback inhibition. Neurob Aging. 1986; 7(5): 331-335, doi: 10.1016/0197-4580(86)90159-4, indexed in Pubmed: 3024042.

132. Sapolsky R, Meaney M. Maturation of the adrenocortical stress response: Neuroendocrine control mechanisms and the stress hyporesponsive period. Brain Res Rev. 1986; 11(1): 65-76, doi: 10.1016/0165-0173(86)90010-x, indexed in Pubmed: 3011218.

133. Scaccianoce S, Del Bianko P, Caricasole, A, et al. Relationship between learning, stress and hippocampal brain-derived neurotrophic factor. Neuroscience. 2003; 121(4): 825-828, doi: 10.1016/s0306-4522(03)00514-1, indexed in Pubmed: 14580931.

134. Scaccianoce S, Bianco PD, Paolone G, et al. Social isolation selectively reduces hippocampal brain-derived neurotrophic factor without altering plasma corticosterone. Behav Brain Res. 2006; 168(2): 323-325, doi: 10.1016/j. bbr.2005.04.024, indexed in Pubmed: 16455145.

135. Schaaf MJ, De Kloet ER, Vreugdenhil E. Corticosterone effects on BDNF expression in the hippocampus. Implications for memory formation. Stress. 2000; 3(3): 201-208, doi: 10.3109/10253890009001124, indexed in Pubmed: 10938581.

136. Schafe G, LeDoux J. Memory consolidation of auditory pavlovian fear conditioning requires protein synthesis and protein kinase $a$ in the amygdala. J Neurosci. 2000; 20(18): RC96-RC96, doi: 10.1523/jneurosci.20-18-j0003.2000, indexed in Pubmed: 10974093.

137. Schmidt MV, Enthoven L, Van der Mark M, et al. The postnatal development of the hypothalamic-pituitary-adrenal axis in the mouse. Int J Dev Neurosci. 2003; 21(3): 125-132, doi: 10.1016/s0736-5748(03)00030-3, indexed in Pubmed: 12711350.

138. Schmidt MV, Scharf SH, Liebl C, et al. A novel chronic social stress paradigm in female mice. Horm Behav. 2010; 57(4-5): 415-420, doi: 10.1016/j.yhbeh.2010.01.010, indexed in Pubmed: 20100488.

139. Schoenfeld NM, Leathem JH, Rabii J. Maturation of adrenal stress responsiveness in the rat. Neuroendocrinology. 1980; 31(2): 101-105, doi: 10.1159/000123058, indexed in Pubmed: 6248807.

140. Schulte-Herbruggen O, Chourbaji S, Muller H, et al. Differential regulation of nerve growth factor and brain-derived neurotrophic factor in a mouse model of learned helplessness. Exp Neurol. 2006; 202(2): 404-409, doi: 10.1016/j. expneurol.2006.07.002, indexed in Pubmed: 16914143.

141. Seo MiK, Ly NN, Lee CH, et al. Early life stress increases stress vulnerability through BDNF gene epigenetic changes in the rat hippocampus. Neuropharmacology. 2016; 105: 388-397, doi: 10.1016/j.neuropharm.2016.02.009, indexed in Pubmed: 26877199.

142. Shao SH, Shi SS, Li ZL, et al. Aging effects on the BDNF mRNA and TrkB mRNA expression of the hippocampus in different durations of stress. Chin J Physiol. 2010; 53(5): 285-293, doi: 10.4077/cjp.2010.amk056, indexed in Pubmed: 21793339.

143. Shi SS, Shao SH, Yuan BP, et al. Acute stress and chronic stress change brain-derived neurotrophic factor (BDNF) and tyrosine kinase-coupled receptor (TrkB) expression in both young and aged rat hippocampus. Yonsei Med J. 2010; 51(5): 661-671, doi: 10.3349/ymj.2010.51.5.661, indexed in Pubmed: 20635439.

144. Shoji H, Mizoguchi K. Acute and repeated stress differentially regulates behavioral, endocrine, neural parameters relevant to emotional and stress response in young and aged rats. Behav Brain Res. 2010; 211(2): 169-177, doi: 10.1016/j. bbr.2010.03.025, indexed in Pubmed: 20307586.

145. Silhol M, Arancibia S, Maurice T, et al. Spatial memory training modifies the expression of brain-derived neurotrophic factor tyrosine kinase receptors in young and aged rats. Neuroscience. 2007; 146(3): 962-973, doi: 10.1016/j.neuroscience.2007.02.013, indexed in Pubmed: 17391859.

146. Silhol M, Bonnichon V, Rage F, et al. Age-related changes in brain-derived neurotrophic factor and tyrosine kinase receptor isoforms in the hippocampus and hypothalamus in male rats. Neuroscience. 2005; 132(3): 613-624, doi: 10.1016/j.neuroscience.2005.01.008, indexed in Pubmed: 15837123.

147. Singh LK, Pang $X$, Alexacos N, et al. Acute immobilization stress triggers skin mast cell degranulation via corticotropin releasing hormone, neurotensin, and substance $P$ : A link to neurogenic skin disorders. Brain Behav Immun. 1999; 13(3): 225-239, doi: 10.1006/brbi.1998.0541, indexed in Pubmed: 10469524.

148. Smith M. Hippocampal vulnerability to stress and aging: possible role of neurotrophic factors. Behav Brain Res. 1996; 78(1): 25-36, doi: 10.1016/0166-4328(95)00220-0, indexed in Pubmed: 8793034.

149. Smith M, Cizza G. Stress-induced changes in brain-derived neurotrophic factor expression are attenuated in aged Fischer 344/N rats. Neurobiol Aging. 1996; 17(6): 859-864, doi: 10.1016/s0197-4580(96)00066-8, indexed in Pubmed: 9363796.

150. Smith MA, Makino S, Kim SY, et al. Stress increases brain-derived neurotropic factor messenger ribonucleic acid in the hypothalamus and pituitary. Endocrinology. 1995; 136(9): 3743-3750, doi: 10.1210/ endo.136.9.7649080, indexed in Pubmed: 7649080.

151. Smith MA, Makino S, Kvetnansky R, et al. Stress and glucocorticoids affect the expression of brain-derived neurotrophic factor and neurotrophin-3 mRNAs in the hippocampus. J Neurosci. 1995; 15(3): 1768-1777, doi: 10.1523/jneurosci.15-03-01768.1995, indexed in Pubmed: 7891134.

152. Solas M, Aisa B, Mugueta M, et al. Interactions between age, stress and insulin on cognition: implications for alzheimer's disease. Neuropsychopharmacology. 2010; 35(8): 1664-1673, doi: 10.1038/npp.2010.13, indexed in Pubmed: 20182419

153. St-Cyr S, McGowan PO. Programming of stress-related behavior and epigenetic neural gene regulation in mice offspring through maternal exposure to predator odor. Front Behav Neurosci. 2015; 9: 145, doi: 10.3389/fnbeh.2015.00145, indexed in Pubmed: 26082698.

154. Tapia-Arancibia L. Physiology of BDNF: focus on hypothalamic function. Front Neuroendocrinol. 2004; 25(2): 77-107, doi: 10.1016/j.yfrne.2004.04.001, indexed in Pubmed: 15571756.

155. Tornese P, Sala N, Bonini D, et al. Chronic mild stress induces anhedonic behavior and changes in glutamate release, BDNF trafficking and dendrite morphology only in stress vulnerable rats. The rapid restorative action of ketamine. 
Neurobiol Stress. 2019; 10: 100160, doi: 10.1016/j.ynstr.2019.100160, indexed in Pubmed: 31193464.

156. Tsankova NM, Berton $O$, Renthal $W$, et al. Sustained hippocampal chromatin regulation in a mouse model of depression and antidepressant action. Nat Neurosci. 2006; 9(4): 519-525, doi: 10.1038/nn1659, indexed in Pubmed: 16501568.

157. Tsigos C, Chrousos G. Hypothalamic-pituitary-adrenal axis, neuroendocrine factors and stress. J Psychosom Res. 2002; 53(4): 865-871, doi: 10.1016/s00223999(02)00429-4, indexed in Pubmed: 12377295.

158. Tsoory M, Cohen H, Richter-Levin G. Juvenile stress induces a predisposition to either anxiety or depressive-like symptoms following stress in adulthood. Eur Neuropsychopharmacol. 2007; 17(4): 245-256, doi: 10.1016/j. euroneuro.2006.06.007, indexed in Pubmed: 16889944.

159. Turecki G, Meaney MJ. Effects of the social environment and stress on glucocorticoid receptor gene methylation: a systematic review. Biol Psychiatry. 2016; 79(2): 87-96, doi: 10.1016/j.biopsych.2014.11.022, indexed in $\mathrm{Pu}$ bmed: 25687413.

160. Tyler WJ, Perrett SP, Pozzo-Miller LD. The role of neurotrophins in neurotransmitter release. Neuroscientist. 2002; 8(6): 524-531, doi: 10.1177/1073858402238511, indexed in Pubmed: 12467374.

161. Ueyama T, Kawai $Y$, Nemoto $K$, et al. mmobilization stress reduced the expression of neurotrophins and their receptors in the rat brain. Neurosci Res. 1997; 28(2): 103-110, doi: S0168-0102(97)00030-8, indexed in Pubmed: 9220467.

162. Ulrich-Lai YM, Herman JP. Neural regulation of endocrine and autonomic stress responses. Nat Rev Neurosci. 2009; 10(6): 397-409, doi: 10.1038/nrn2647, indexed in Pubmed: 19469025 .

163. Valzelli L. The "isolation syndrome" in mice. Psychopharmacologia. 1973; 31(4): 305-320, doi: 10.1007/ BF00421275, indexed in Pubmed: 4582344.

164. van Zyl PJ, Dimatelis JJ, Russell VA. Behavioural and biochemical changes in maternally separated Sprague-Dawley rats exposed to restraint stress. Metab Brain Dis. 2016; 31(1): 121-133, doi: 10.1007/s11011-015-9757-y, indexed in Pubmed: 26555398.

165. Vázquez DM, Akil H. Pituitary-adrenal response to ether vapor in the weanling animal: characterization of the inhibitory effect of glucocorticoids on adrenocorticotropin secretion. Pediatr Res. 1993; 34(5): 646-653, doi: 10.1203/00006450-199311000-00017, indexed in Pubmed: 8284104.

166. Veenema A, Blume A, Niederle D, et al. Effects of early life stress on adult male aggression and hypothalamic vasopressin and serotonin. Eur J Neurosci. 2006; 24(6): 1711-1720, doi: 10.1111/j.1460-9568.2006.05045.x, indexed in Pubmed: 17004935.

167. Viana Borges J, Souza de Freitas B, Antoniazzi V, et al. Social isolation and social support at adulthood affect epigenetic mechanisms, brain-derived neurotrophic factor levels and behavior of chronically stressed rats. Behav Brain Res. 2019; 366: 36-44, doi: 10.1016/j. bbr.2019.03.025, indexed in Pubmed: 30880220.

168. Weaver IC, Cervoni N, Champagne F, et al. Epigenetic programming by maternal behavior. Nature Neurosci. 2004; 7(8): 847-854, doi: $10.1038 / \mathrm{nn} 1276$, indexed in Pubmed: 15220929.
169. Whitnall M. Regulation of the hypothalamic corticotropin-releasing hormone neurosecretory system. Prog Neurobiol. 1993; 40(5): 573-629, doi: 10.1016/03010082(93)90035-q, indexed in Pubmed: 8484004.

170. Willner P, Towell A, Sampson D, et al. Reduction of sucrose preference by chronic unpredictable mild stress, and its restoration by a tricyclic antidepressant. Psychopharmacology. 1987; 93(3): 538-564, doi: 10.1007/bf00187257, indexed in Pubmed: 3124165.

171. Xu H, Chen Z, He J, et al. Synergetic effects of quetiapine and venlafaxine in preventing the chronic restraint stress-induced decrease in cell proliferation and BDNF expression in rat hippocampus. Hippocampus. 2006; 16(6): 551-559, doi: 10.1002/hipo.20184, indexed in Pubmed: 16652337.

172. Xu H, Luo C, Richardson JS, et al. Recovery of hippocampal cell proliferation and BDNF levels, both of which are reduced by repeated restraint stress, is accelerated by chronic venlafaxine. Pharmacogenomics J. 2004; 4(5): 322-331, doi: 10.1038/sj.tpj.6500265, indexed in Pubmed: 15289796.

173. Xu H, Qing H, Lu W, et al. Quetiapine attenuates the immobilization-induced decrease of brain-derived neurotrophic factor in rat hippocampus. Neurosci Lett . 2002; 321(1-2): 65-68, doi: 10.1016/s0304-3940(02)00034-4, indexed in Pubmed: 11872258.

174. Xue X, Shao S, Wang W, et al. Maternal separation induces alterations in reversal learning and brain-derived neurotrophic factor expression in adult rats. Neuropsychobiology. 2013; 68(4): 243-249, doi: 10.1159/000356188, indexed in Pubmed: 24280707.

175. Yoshii A, Constantine-Paton M. Postsynaptic BDNF-TrkB signaling in synapse maturation, plasticity, and disease. Dev Neurobiol. 2010; 70(5): 304-322, doi: 10.1002/ dneu.20765, indexed in Pubmed: 20186705.

176. Yun SJ, Park HJ, Yeom MJ, et al. Effect of electroacupuncture on the stress-induced changes in brain-derived neurotrophic factor expression in rat hippocampus. Neurosci Lett. 2002; 318(2): 85-88, doi: 10.1016/s03043940(01)02492-2, indexed in Pubmed: 11796192.

177. Zaletel I, Filipović D, Puškaš N. Hippocampal BDNF in physiological conditions and social isolation. Rev Neurosci. 2017; 28(6): 675-692, doi: 10.1515/revneuro-2016-0072, indexed in Pubmed: 28593903.

178. Zheng Yu, Fan W, Zhang X, et al. Gestational stress induces depressive-like and anxiety-like phenotypes through epigenetic regulation of BDNF expression in offspring hippocampus. Epigenetics. 2016; 11(2): 150-162, doi: 10.1080/15592294.2016.1146850, indexed in Pubmed: 26890656.

179. Zimmerberg B, Foote HE, Van Kempen TA. Olfactory association learning and brain-derived neurotrophic factor in an animal model of early deprivation. Dev Psychobiol. 2009; 51(4): 333-344, doi: 10.1002/dev.20373, indexed in Pubmed: 19308959.

180.Zoladz PR, Park CR, Halonen JD, et al. Differential expression of molecular markers of synaptic plasticity in the hippocampus, prefrontal cortex, and amygdala in response to spatial learning, predator exposure, and stress-induced amnesia. Hippocampus. 2012; 22(3): 577-589, doi: 10.1002/hipo.20922, indexed in Pubmed: 21538655. 